Indian J Anim Health (2021), 60(2): 272-273

DOI: https://doi.org/10.36062/ijah.2021.01421

\title{
A case report on successful management of dystocia due to incomplete cervical dilation in sheep
}

\author{
L. Kipjen Singh ${ }^{1 *}$, U. Singh ${ }^{1}$, C. Chaudhary ${ }^{2}$ and P. Singh ${ }^{2}$
}

${ }^{1}$ Department of Veterinary Gynaecology and Obstetrics, International Institute of Veterinary Education and Research, Rohtak, Haryana-124 001, India; ${ }^{2}$ Department of Veterinary Clinical Complex, International Institute of Veterinary Education and Research, Rohtak, Haryana-124 001, India

\begin{abstract}
The current communication describes a case study on the successful management of dystocia due to incomplete cervical dilation in a non-descript sheep presented at Veterinary Clinical Complex, International Institute of Veterinary Education and Research (IIVER), Rohtak, Haryana. The local non-descript sheep had an anamnesis of non-progression of labor after a full term. Vaginal examination revealed one finger dilation of the external os-cervix. Estrogen@ $2 \mathrm{~mL}$ and dexamethasone @ $2 \mathrm{~mL}$ was administered intramuscularly for dilation of the cervix. Two dead fetuses were delivered successfully by manual traction.
\end{abstract}

Key words: Dexamethasone, Dystocia, Estrogen, Sheep

Dystocia is defined as an abnormality or difficulty in birth due to long, unassisted parturition or prolonged delivery requiring assistance (Zaborski et al., 2009). The cause of dystocia may be of maternal or fetal origin (Noakes et al., 2009). Ringwomb i.e. failure of cervical dilation is reported to be the most important cause of sheep dystocia (Bhattacharyya et al., 2015).The incidence of obstruction of the birth canal due to insufficient cervical dilation has been reported to be 25-50\% (Purohit et al., 2006) in sheep. Manual correction and cesarean section of ringwomb were attempted by several authors with different success rates (Jackson, 2004; Ismail, 2017). Thus, the present article communicates the medical management of ringwomb followed by manual delivery in a local non-descript sheep.

A full-term pregnant non-descript sheep in its $7^{\text {th }}$ parity was presented to Veterinary Clinical Complex, International Institute of Veterinary Education and Research, Haryana with a history of no progression of labor (Fig.1). Feed and water intake were normal. Two fetuses were felt inside the uterus by trans-abdominal palpation.
Per vaginal examination revealed one finger dilation of the external os of the cervix with reddish-brown discharge. The case was diagnosed as dystocia due to incomplete dilation of the cervix.

The animal was initially treated with corticosteroid i.e. Inj. Dexona @ $2 \mathrm{~mL}$ intramuscularly and estrogen i.e. Inj. Qikhit@ $2 \mathrm{~mL}$ intramuscularly. Following dilation therapy, the appearance of water bag rupture was observed after 12 hours but there was no further progression of parturition. Per vaginal examination revealed a fully dilated cervix with the fetus in anterior presentation and dorso sacral position. Since the animal appeared anorectic and depressed, the animal was stabilized with intravenous infusion of $500 \mathrm{~mL}$ DNS. The animal was restrained properly with $2 \mathrm{~mL}$ of $2 \%$ xylocaine injected epidurally in a standing position and the birth canal was fully lubricated using liquid paraffin. Manual traction was applied and two dead fetuses along with the placenta were removed successfully (Fig. 2). This was followed by the application of 2 Furex boli inside the uterus for clearance of infection. The

*Corresponding Author, E mail: laishramkipjen04@gmail.com 
Indian Journal of Animal Health, December, 2021

Management of incomplete cervical dilation in sheep

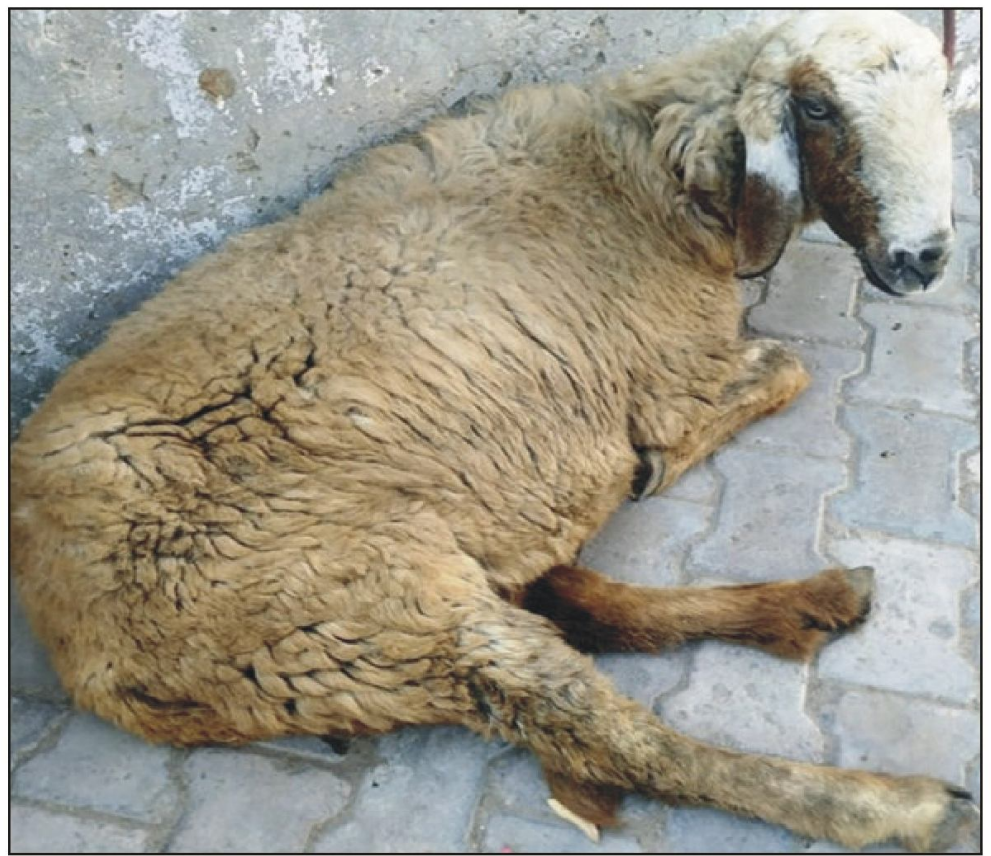

Fig. 1. Photograph showing the condition of sheep presented in clinics

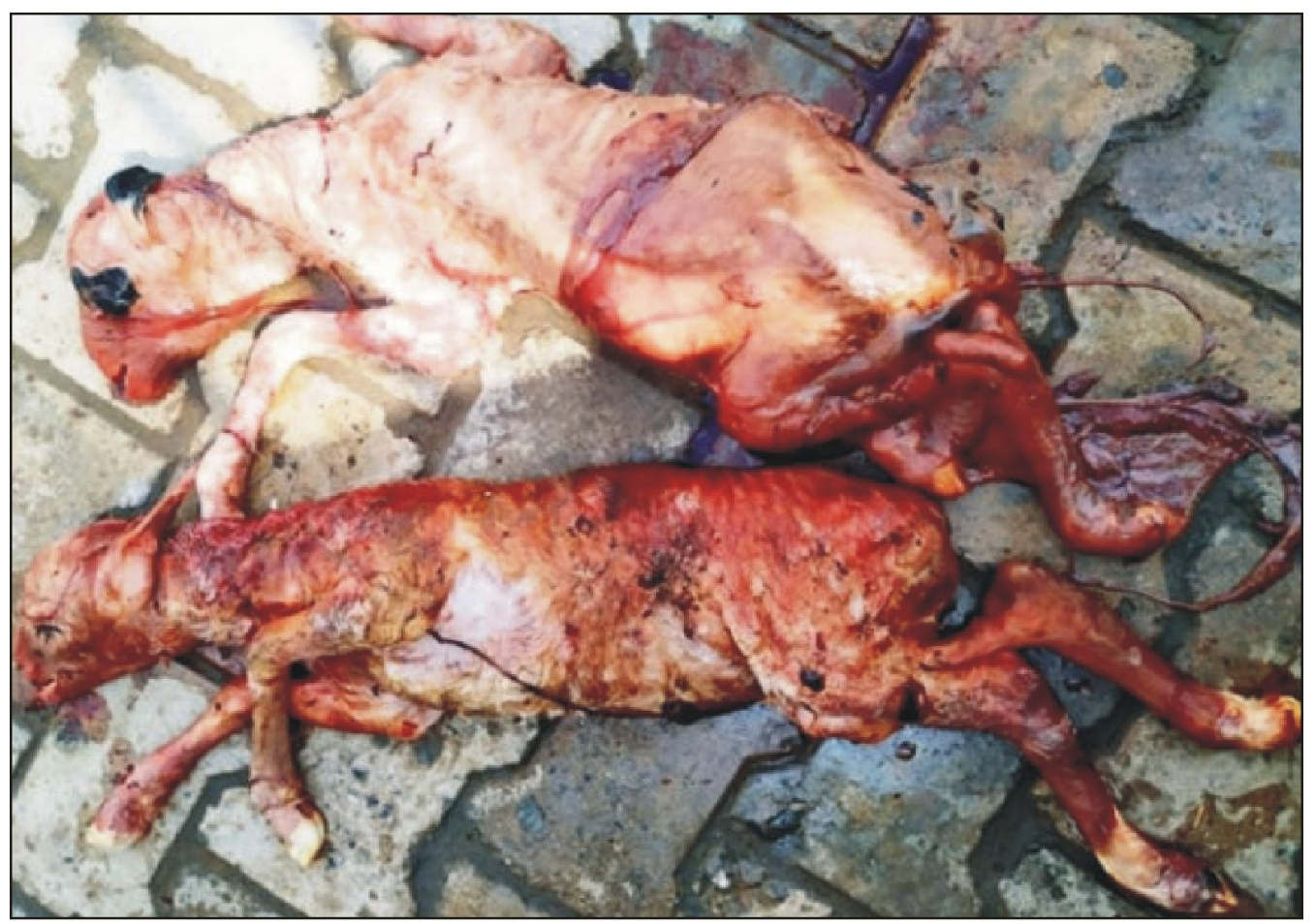

Fig. 2. Photograph showing the dead fetuses 
animal was treated with Inj. enrofloxacin (Fortivir)@ 2 mL I/M, Inj. vit. B1, B6, B12 (Tribivet)@2 mL I/M, Inj. meloxicum (Melonex) @ $2 \mathrm{~mL}$ I/M and Inj. calcium @2 $\mathrm{mL} \mathrm{I/M}$ for consecutive 4 days and the dam recovered uneventfully.

In the present communication, dystocia in sheep was due to failure of the cervix to dilate during parturition also known as ringwomb. Ringwomb is reported as the main contributor to maternal dystocia (Ennen et al., 2013; Mostefai et al., 2019). Several researchers reported various medicinal therapies and surgical procedures for treating ringwomb with variable success (Hanie, 2006; Ali, 2011). Similarly, the application of dexamethasone and estrogen was done for dilation of the cervix. The failure of the fetus to expel out after dilation of the cervix may be due to ringwomb followed by uterine inertia.

\section{REFERENCES}

Ali AMH, 2011. Causes and management of dystocia in small ruminants in Saudi Arabia. J Agric Vet Sci, 4(2): 95-108

Bhattacharyya HK, Fazili MR, Bhat FA and Buchoo BA, 2015. Prevalence of dystocia in sheep and goats: A study of 70 cases (2004-2011). J Adv Vet Anim Res, 5(1): 14-20

Ennen S, Scholz M, Voigt K, Failing K and Wehrend A, 2013. Puerperal development of ewes following dystocia: A retrospective analysis of two approaches to caesarean section. Vet Rec, 172(21): 554, doi: 10.1136/vr. 101370

Hanie EAA, 2006. Large Animal Clinical Procedures for Veterinary Technicians. Elsevier, Mosby, Missouri, pp 413-431

Holmoy IH, Waage S, Granquist EG, L'Abee-Lund TM, Ersdal C et al., 2017. Early neonatal lamb mortality: postmortem findings. Animal, 11(2): 295-305, doi: 10.1017/S175173111600152X

Ismail ZB, 2017. Dystocia in sheep and goats: outcome and fertility following surgical and non-surgical management. Maced Vet Rev, 40(1): 91-96, doi: 10.1515/macvetrev-2017-0012
Purohit (2006) reported that incomplete cervical dilation is the major maternal cause of dystocia followed by uterine inertia. The death of the fetus may be due to dystocia. It is reported that dystocia is a significant contributor to lamb deaths across all litter sizes (Holmoy et al., 2017; Kenyon et al., 2019). In conclusion, estrogen and dexamethasone can be attempted for dilation of the cervix in sheep.

\section{ACKNOWLEDGEMENTS}

The authors are highly grateful to the Chairman and Dean, International Institute of Veterinary Education and Research, Rohtak, Haryana for providing facilities to conduct the study.

Conflict of interest: Authors have no conflict of interest in this study.

Jackson PGG, 2004. Dystocia in the Ewe. Chapter 6, In: Jackson, P.G.G. (edn.), Handbook of Veterinary Obstetrics ( $2^{\text {nd }}$ edn.) W. B. Saunders, Oxford, pp $105-124$

Kenyon PR, Roca Fraga FJR, Blumer S and Thompson AN, 2019. Triplet lambs and their dams - A review of current knowledge and management systems. New Zealand J Agric Res, 62(4): 399-437, doi: $10.1080 / 00288233.2019 .1616568$

Mostefai E, Kouidri M and Selles SMA, 2019. Causes of sheep dystocia in Djelfa area (Algeria). Rev Mar Sci Agron Vet, 7(2): 284-287

Noakes DE, Parkinson TJ and England GCW, 2009. Veterinary Reproduction and Obstetrics. London, Saunders, pp 205-217

Purohit GN, 2006. Dystocia in the sheep and goat- A Review. Indian J Small Ruminants, 12(1): 1-12

Purohit GN, Gupta AK, Gaur M, Sharma A and Bihani D, 2006. Periparturient disorders in goats. A retrospective analysis of 324 cases. Dairy Goat J, 84(2): 24-33

Zaborski D, Grzesiak W, Szatkowska I, Dybus A Muszynska M et al., 2009. Factors affecting dystocia in cattle. Reprod Domest Anim, 44(3): 540-551, doi: 10.1111/j.1439-0531.2008.01123.x

Received - 19.04.2021, Accepted - 10.06.2021, Published - 29.08.2021 (Online), 01.12.2021 (Print)

Section Editor: Prof. S. K. Nandi, Associate Editor 